\title{
MODEL SELF MANAGEMENT EDUCATION (SME) DALAM MENINGKATKAN KEMAMPUAN DETEKSI DINI HIPOGLIKEMIA PADA DIABETESI DI RSUD DR MOEWARDI SURAKARTA
}

\author{
Siti Lestari, Tri Sunaryo \\ Kementerian Kesehatan Politeknik Kesehatan Surakarta Jurusan Keperawatan
}

\begin{abstract}
Self-Management Education, Hypoglycemia. Diabetes Mellitus is a metabolic disease that need attention and care for long time in order to prevent complications. People with DM must have good kno ledge, skill and behavior so they can manage their live by themselves. Research showed that 50-80\%, people with DM have not enough knowledge to manage their disease. Through the self-management, people with diabetes can improve their competence in early detection of hypoglycemia so it would be increase the quality of life and reduce the risk of developing complications. The purpose of this study was to investigate the impact of diabetes self-management education toward early detection of hypoglycemic among patients with diabetes. A quasi-experimental pre and post design with control group was used to investigate the impact of using education on self-management. The participants were 40 that divided into intervention and control group. Purposive sampling was used to take the samples. T-Test was used to analyze the data. The competence of diabetes in early detection of hypoglycemia was increase, from 6,1 with SD 13.7 to 71,7 with SD 19.2 . Then, the model of Self Management education influenced the competence of people with diabetes in the early detection of hypoglycemia, $P$ value $0,011(\alpha=0,05)$. The findings demonstrate that the selfmanagement education could improve competence of diabetes in the early detection of hypoglycemia.
\end{abstract}

Keyword : Self-Management Education, Hypoglycemia.

Abstrak: Self-Management Education, Hypoglikemia. Diabetes Mellitus merupakan penyakit metabolik yang membutuhkan perhatian dan perawatan yang lama untuk mencegah komplikasi. Penderita DM seharusnya memiliki pengetahuan, ketrampilan dan perilaku yang baik sehingga mereka akan dapat mengatur kehidupan secara mandiri. Penelitian menunjukkan bahwa 50-80\%, penderita DM tidak mempunyai pengetahuan yang cukup baik untuk mengatur penyakitnya. Melalui self-management education, penderita DM akan meningkat kemampuannya dalam deteksi dini hypoglycemia sehingga akan meningkatkan kualitas hidup dan menurunkan berkembangnya komplikasi. Penelitian ini adalah untuk mengetahui pengaruh self management education terhadap peningkatan kemampuan deteksi dini hipoglikemia dengan pada Diabetesi (penderita DM). Metode penelitian yang digunakan adalah quasi-eksperimental dengan pre test and post test design with control group. Responden sebanyak 40 untuk kelompok intervensi dan control diambil dengan purposive sampling. Analisa data yang dipakai adalah uji t- Independent. Hasil penelitian menunjukkan bahwa terdapat kenaikan kemampuan dalam mendeteksi dini 
hipoglikemia dari 13.7 dengan SD menjadi 71,7 dengan SD 19.2 6,1. Penggunaan Model Self Management Education berpengaruh terhadap peningkatan kemampuan deteksi hipoglikemia pada pasien diabetes, uji statistik uji t- Independent didapatkan $\mathrm{P}$ value $0,011(\alpha=0,05)$. Self management education dapat meningkatkan kemampuan deteksi dini hipoglikemia dengan pada Diabetesi (penderita DM).

Kata Kunci : Self-Management Education, Hypoglikemia.

\section{PENDAHULUAN}

Diabetes melitus merupakan suatu kelompok penyakit metabolik dengan karakteristik hiperglikemia, yang terjadi karena kelainan sekresi insulin, kelainan kerja insulin, atau keduanya. Hiperglikemia kronik pada diabetes berhubungan dengan kerusakan jangka panjang, disfungsi, atau kegagalan beberapa organ tubuh, terutama mata, ginjal, saraf, jantung, dan pembuluh darah.

WHO memperkirakan bahwa 177 juta penduduk dunia mengidap diabetes dan jumlah ini akan meningkat hingga melebihi 300 juta pada tahun 2025. Pada tahun 2025, Asia diperkirakan mempunyai populasi diabetes terbesar di dunia, yaitu 82 juta orang dalam jumlah ini akan meningkat menjadi 366 juta setelah 25 tahun (Purnomo, 2009). Untuk Indonesia, WHO memprediksi kenaikan jumlah penderita diabetes dari 8,4 juta pada tahun 2000 menjadi sekitar 21,3 juta pada tahun 2030 (Diehl, 2004).

Penyakit ini membutuhkan perhatian dan perawatan medis dalam waktu lama baik untuk mencegah komplikasi maupun perawatan sakit. Oleh karena nya, penderita perlu memilliki pengetahuan dan perilaku yang baik sehingga akan mandiri untuk mengatur atau merawat penyakitnya. Beberapa penelitian mencatat bahwa 50-80\% diabetisi memiliki pengetahuan dan ketrampilan yang kurang dalam mengelola penyakitnya (Norris, Engelgau, \& Narayan, 2001; Palestin, Ermawan, \& Donsu, 2005), dan kontrol terhadap kadar gula darah ideal .

Self management memiliki makna bahwa seseorang harus membuat pilihan dan keputusan tentang bagaimana mengatur kehidupan dan DM nya. Melalui self management yang baik, penderita DM dapat meningkatkan kualitas hidupnya dan mengurangi resiko komplikasi. Hal tersebut juga dapat membantu mencegah hospitalisasi penderita. Untuk dapat mengatur diri sendiri dengan baik diperlukan suatu edukasi.

Edukasi atau penyuluhan kesehatan tentang perawatan pasien diabetes melitus merupakan tindakan keperawatan yang harus diberikan untuk meningkatkan motivasi pasien dalam mengendalikan diabetusnya dan regimen terapeutik di rumah efektif serta menghindarkan terjadinya hospitalisasi ulang serta mencegah terjadinya komplikasi. Edukasi yang harus diberikan kepada klien atau orang tuanya meliputi diet, monitoring glukosa darah, aktivitas fisik, perawatan kaki " foot care ", dan terapi farmakologi, termasuk edukasi cara penyimpanan obat, dosis serta daerah-daerah pada tubuh yang dapat digunakan sebagai tempat absorbsi insulin. Tanda dan cara mengatasi hipoglikemia dan hiperglikemia juga perlu diajarkan kepada pasien atau keluarga. Hipoglikemia adalah salah satu komplikasi yang dihadapi oleh penderita 
diabetes melitus. Tidak seperti nefropati diabetik ataupun retinopati diabetik yang berlangsung secara kronis, hipoglikemia dapat terjadi secara akut dan tiba tiba dan dapat mengancam nyawa. Hal tersebut disebabkan karena glukosa adalah satu satunya sumber energi otak dan hanya dapat diperoleh dari sirkulasi darah karena jaringan otak tidak memiliki cadangan glukosa. Kadar gula darah yang rendah pada kondisi hipoglikemia dapat menyebabkan kerusakan sel -sel otak. Kondisi inilah yang menyebabkan hipoglikemia memiliki efek yang fatal bagi penyandang diabetes melitus, di mana 2\%-4\% kematian penderita diabetes melitus disebabkan oleh hipoglikemia.

\section{METODE PENELITIAN}

Desain penelitian ini adalah quasieksperimental dengan pre test and post test design with control group, dimana desain ini melakukan tindakan pada dua atau lebih kelompok yang akan diobservasi sebelum dan sesudah dilakukan tindakan.. Kelompok A disebut kelompok intervensi yang memperoleh kombinasi self management education dan terapi standar DM, sedangkan kelompok B disebut sebagai kelompok kontrol yang hanya memperoleh terapi standar DM .

Gambar 4.1 Desain Penelitian

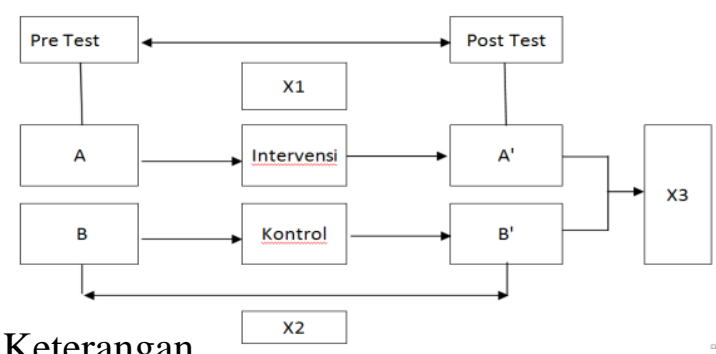

Keterangan

A : Kemampuan deteksi hipoglikemia pada kelompok intervensi sebelum dilakukan Self management education.
A' : Kemampuan deteksi hipoglikemia pada kelompok intervensi sesudah dilakukan Self management education.

B : Kemampuan deteksi hipoglikemia pada kelompok control sebelum kelompok intervensi mendapat perlakuan self management education

B' : Kemampuan deteksi hipoglikemia pada kelompok control sesudah kelompok intervensi mendapat perlakuan self management education

X1 : Perubahan Kemampuan deteksi hipoglikemi pada kelompok intervensi sebelum dan sesudah dilakukan Self management education

X2 : Perubahan Kemampuan deteksi hipoglikemi pada kelompok intervensi sebelum dan sesudah dilakukan Self management education

X3 : Perbedaan Kemampuan deteksi hipoglikemi kelompok intervensi dan kelompok control sesudah dilakukan Self management education

\section{HASIL PENELITIAN}

Uji homogenitas pada kelompok intervensi dan kontrol dengan menggunakan one way Anova didapatkan $\mathrm{p}$ value 0,443 maka dapat disimpulkan bahwa terdapat kesetaraan (homogen) karakteristik pada kelompok intervensi dan kontrol, sehingga bila terdapat perbedaan setelah dilakukan intervensi, maka perbedaan itu sebagai akibat dari intervensi.

Uji Normalitas kolmogorov smirnov didapatkan $\mathrm{P}$ value 0,200 atau pada pengujian lain didapatkan nilai Skewness 0,283 dan Standar errornya 0,374 sehingga bila nilai Skewness dibagi nilai Standar errornya didapatkan nilai $0,76(<2)$. Berdasarkan nilai tersebut dapat disimpulkan bahwa distribusi data normal. 
Tabel 1

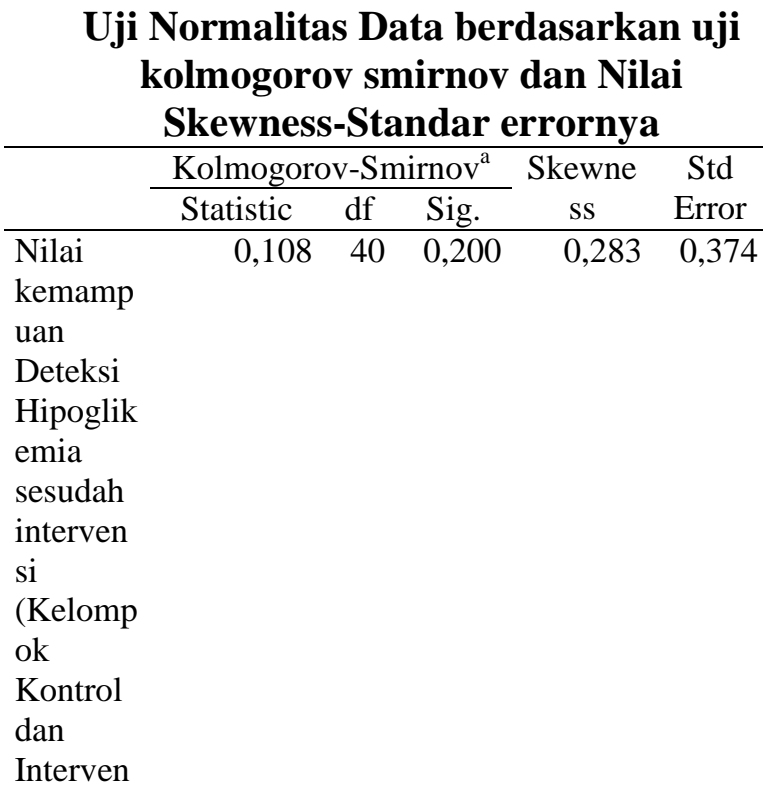

si)

Rerata nilai kemampuan mendeteksi hipoglikemia pada kelompok intervensi sebelum pemberian Model Self Management Education 61,0 dengan standar deviasi 13,7. Nilai terendah kemampuan mendeteksi hipoglikemia 37 dan tertinggi 87. Sedangkan setelah pemberian Model Self Management Education rerata nilai kemampuan mendeteksi hipoglikemia 71,7 dengan standar deviasi 19,2. Nilai terendah kemampuan mendeteksi hipoglikemia 37 dan tertinggi 97. Karakteristik Responden Berdasarkan Kemampuan Mendeteksi Hipoglikemia Sebelum Dan Sesudah Intervensi pada kelompok Intervensi tertuang dalam Tabel 2

\section{Tabel 2}

Responden Berdasarkan Kemampuan Mendeteksi Hipoglikemia Sebelum Dan Sesudah Intervensi

\begin{tabular}{lcc}
\hline & Sebelum & Sesudah \\
\hline Mean & 61,0 & 71,7 \\
SD & 13,7 & 19,2 \\
Minimal - & $37-87$ & $37-$ \\
\hline
\end{tabular}

Maksimal 97

Hasil uji statistik menunjukkan bahwa $\mathrm{P}$ value pada kelompok Intervensi sebesar $0,000 \quad(\alpha=0,05)$ sehingga dapat disimpulkan bahwa Penggunaan Model Self Management Education berpengaruh terhadap peningkatan kemampuan deteksi hipoglikemia Sebelum dan Sesudah pemberian pendidikan kesehatan melalui Model Self Management Education pada kelompok Intervensi, sebagaimana tertuang dalam hasil uji statistik Tabel 3

Tabel 3

Distribusi Rerata Kemampuan Deteksi Hipoglikemia Pada Kelompok

Intervensi Sebelum dan Sesudah

Penggunaan Model Self Management Education di RSUD Dr Moewardi Surakarta

\begin{tabular}{lccclc}
\hline Variabel & Mean & SD & SE & $\begin{array}{l}\text { P } \\
\text { Value }\end{array}$ & N \\
\hline Pre & & & & & \\
Intervensi & 61,00 & 13,68 & 3,06 & 0,000 & 20 \\
$\begin{array}{l}\text { Post } \\
\text { Intervensi }\end{array}$ & 71,67 & 19,24 & 4,30 & & \\
\hline \multicolumn{1}{r}{ Uji } & statistik & Levene's & Test
\end{tabular}
didapatkan $\mathrm{P}$ value $0,002(\alpha=0,05)$ maka hal ini menunjukkan varian berbeda, sehinggga pada uji statistik uji tIndependent didapatkan P value 0,011 ( $\alpha$ $=0,05)$ berarti penggunaan Model Self Management Education berpengaruh terhadap peningkatan kemampuan deteksi hipoglikemia pada pasien diabetes. Secara rinci dapat dilihat pada Tabel 4 dibawah ini

Tabel 4

Perbedaan Kemampuan Deteksi Hipoglikemia Sebelum dan Sesudah Penggunaan Model Self Management Education Pada kelompok Intervensi Dan Kelompok Kontrol di RSUD Dr Moewardi Surakarta 


\begin{tabular}{lll}
\hline Kelompok & $\begin{array}{l}\text { Levene's } \\
\text { Test }\end{array}$ & P Value \\
\hline $\begin{array}{l}\text { Perbedaan } \\
\text { Kemampuan }\end{array}$ & & \\
$\begin{array}{l}\text { Deteksi } \\
\text { Hipoglikemia } \\
\text { pada kelompok }\end{array}$ & 0,002 & 0,011 \\
$\begin{array}{l}\text { Intervensi- } \\
\text { intervensi }\end{array}$ & & \\
\hline
\end{tabular}

\section{PEMBAHASAN}

Hasil uji statistik didapatkan bahwa $\mathrm{P}$ value pada kelompok Intervensi sebesar $0,000 \quad(\alpha=0,05) \quad$ sehingga dapat disimpulkan bahwa Penggunaan Model Self Management Education berpengaruh terhadap peningkatan kemampuan deteksi hipoglikemia.

Edukasi merupakan upaya agar masyarakat berperilaku atau mengadopsi perilaku kesehatan dengan cara persuasi, bujukan, himbauan, ajakan, memberikan informasi, memberikan kesadaran, dan sebagainya melalui kegiatan yang disebut pendidikan atau penyuluhan kesehatan. Pemberian pendidikan kesehatan ditujukkan untuk menggugah kesadaran, memberikan atau meningkatkan pengetahuan masyarakat tentang pemeliharaan dan peningkatan kesehatan baik bagi diri sendiri, keluarga maupun masyarakat(Notoatmodjo, 2003).

Self Management Education merupakan suatu proses berkelanjutan yang dilakukan untuk mengembangkan kesadaran atau pengetahuan, keterampilan, dan kemampuan pasien DM untuk melakukan perawatan mandiri (Funnell MM, et al, 2008; Cooper H, Boooth, K, Gill,G.2003; Patterson,B., Thorne, S(2000) dan memberikan pengetahuan atau edukasi kepada pasien mengenai aplikasi strategi perawatan diri secara mandiri untuk mengoptimalkan control metabolik, mencegah komplikasi, dan memperbaiki kualitas hidup pasien DM (Sidani S, Fan L, 2009). Pendekatan SME sangat bervariasi, diawali dengan pengkajian kebutuhan pembelajaran, menetapkan tujuan, mengintervensi pasien dan diakhiri dengan evaluasi. Proses tersebut bisa dilakukan secara kelompok maupun individu. Dalam penelitian ini, proses SME dilakukan secara individual. Diawali dengan menentukan tujuan pembelajaran. Tujuan pembelajaran yang disusun bersama antara penderita dan petugas akan memudahkan penerimaan edukasi yang diberikan, karena penderita merasa sangat dihargai dan mengetahui kebutuhan mereka akan pembelajaran sehingga akan muncul keterbukaan dan motivasi yang tinggi .

Keterbukaan dan motivasi sangat diperlukan untuk proses edukasi. Keberhasilan suatu program edukasi juga dipengaruhi oleh motivasi dari diri sendiri. Menurut The Royal Australian College of General Practioners (2010) dalam penelitian SME pada penderita hipertensi, menjelaskan bahwa perilaku self management hipertensi salah satunya dipengaruhi oleh motivasi, dimana motivasi seseorgang akan dipengaruhi dan meningkat seiring dengan perubahan yang dialami oleh pasien. Hal ini diperkuat oleh hasil penelitian Akinsola (2001) yang menyatakan bahwa sesorang yang melakukan self-management dengan baik dipengaruhi oleh pengetahuan, keterampilan, sikap yang positif, keyakinan dan optimis untuk meningkatkan kesehatan yang buruk.

Tinjauan diatas sesuai dengan penelitian yang dilakukan oleh Naccashian, Z (2014) terhadap 75 responden di Amerika, bahwa Self Management Education terbukti 
memiliki pengaruh yang positif terhadap kemampuan mengatur diri sendiri, dalam hal ini adalah mengontrol glukosa darah atau glicemic controll .

Diagnosa keperawatan yang mungkin ditegakkan berkaitan dengan edukasi adalah Tidak adanya atau kurangnya informasi kognitif berhubungan dengan keterbatasan kognitif, interpretasi terhadap informasi yang salah, kurangnya keinginan untuk mencari informasi, tidak mengetahui sumber-sumber informasi.

Intervensi yang dilakukan untuk meningkatkan kompetensi diabetesi adalah memberikan informasi atau edukasi tentang proses penyakit, perawatan dan pencegahan komplikasi. Edukasi dapat diberikan melalui suatu promosi kesehatan. Promosi kesehatan merupakan proses pemberdayaan atau memandirikan masyarakat agar dapat memelihara dan meningkatkan kesehatannya. Proses pemberdayaan atau memandirikan masyarakat tidak hanya terbatas pada pemberian informasi (seperti pendidikan kesehatan) tetapi juga upaya untuk merubah perilaku dan sikap seseorang, sehingga promosi kesehatan dapat meningkatkan kemampuan kognitif, afektif, dan psikomotor seseorang (Maulana, 2009).

\section{KESIMPULAN DAN SARAN}

Kesimpulan yang dapat ditarik dari hasil penelitian ini :

1. Rerata nilai kemampuan mendeteksi hipoglikemia pada kelompok intervensi sebelum pemberian Model Self Management Education 61,0 dengan standar deviasi 13,7. Nilai terendah kemampuan mendeteksi hipoglikemia 37 dan tertinggi 87 .
Sedangkan setelah pemberian Model Self Management Education rerata nilai kemampuan mendeteksi hipoglikemia 71,7 dengan standar deviasi 19,2. Nilai terendah kemampuan mendeteksi hipoglikemia 37 dan tertinggi 97

2. Penggunaan Model Self Management Education berpengaruh terhadap peningkatan kemampuan deteksi hipoglikemia, $\mathrm{P}$ value pada kelompok Intervensi sebesar $0,000(\alpha=0,05)$.

3. Penggunaan Model Self Management Education berpengaruh terhadap peningkatan kemampuan deteksi hipoglikemia pada pasien diabetes, uji statistik uji t- Independent didapatkan $\mathrm{P}$ value $0,011(\alpha=0,05)$.

Berdasarkan hasil penelitian ini saran yang dapat diberikan adalah :

1. Model Self Management Education dapat digunakan sebagai salah satu program promosi kesehatan pada pelayanan kesehatan dan dapat diadopsi sebagai materi pokok dalam pembelajaran atau perkuliahan

2. Model Self Management Education dapat dijadikan sebagai sumber informasi dan acuan bagi perawat, mahasiswa, dosen, institusi pelayanan kesehatan, dan peneliti lain yang ingin melakukan penelitian terkait pemberian DSME dan DM .

3. Penelitian lanjutan yang dilakukan dapat menggunakan jangka waktu yang lebih lama atau jenis penelitian ekperimen murni, seperti penelitian longitudinal atau randomized control trial dengan sampel yang lebih besar dapat 
dilakukan untuk mengevaluasi pengaruh Self Management Education terhadap self care behavior pasien DM.

\section{DAFTAR RUJUKAN}

Cooper HC, Booth K, Gill G: Patients' perspectives on diabetes health care education. Theory Pract 2003, 18:191-206.

Diehl, Hans. 2004. To Your Health : Demi Kesehatan Anda. Bandung: IPH

Funnell MM, (2008) . National Standards for Diabetes Self-Management Education. Diab Care. 31 (1): S87-S94
Maulana HDJ. (2009). Promosi Kesehatan. Jakarta: EGC

Norris, S.L., Engelgau, M.M., \& Narayan, K.M.V., (2001). Effectiveness of Self-

Norris, SL, Nichols, PJ, Caspersen,CJ, Glasgow, Engelgau, M. Jack Jr, L.Snyder,

Notoatmodjo, S., (2003), Metodologi Penelitian Kesehatan, Jakarta, Rineka Cipta.

Sidani S, Fan L.(2009) Effectiveness of Diabetes Self-management Education

WHO : The cost of Diabetes, Retrieved fromhttp://www.who.int/mediacent re/factsheets/fs236/en/ 